\title{
Effects of risk as a within-subject variable in probability learning'
}

\author{
Stanley G. Lipkin, John A. Sehnorr, Mary M. Suydam and Jerome L. Myers \\ UNIVERSITY OF MASSACHUSETTS
}

\begin{abstract}
Levels of risk were varied within Ss in a two-choice probability learning experiment. Contrary to the results of studies where risk was varied between Ss, the probability of predicting the more frequent event, $\mathrm{P}\left(\mathrm{A}_{1}\right)$, was significantly greater at high than at low risk. A second finding was that $\mathrm{P}\left(\mathrm{A}_{1}\right)$ was significantly higher for male than for female Ss, regardless of risk level.

\section{Problem}

In a recent review of the literature on animal learning, Pubols (1960) concluded that variation in incentive magnitude has no significant effect on time-independent measures of learning when an absolute method is used (i. e., each S receives only a single incentive level), but that incentive effects are obtained when a differential method is employed (i. e., each $\mathrm{S}$ experiences more than one incentive level). Experiments involving the effects of risk on human choice behavior have yielded results which are consistent with Pubols' conclusions regarding the absolute method. For example, Myers et al (1963) reported that the probability of choosing the more frequent of two events was not significantly greater for a 10 cent- than for a 1 cent-risk group. The purpose of the present study was to determine whether the differential method of incentive presentation would affect human choice behavior. More specifically, on each trial Ss were first informed which of two amounts was to be risked, and then required to predict which of two events would occur.
\end{abstract}

\section{Method}

In the first of two experiments, six male and six female Ss, undergraduate volunteers from the University of Massachusetts, were required to predict which of two events would occur on each of 500 trials. The two events were low-associative nonsense syllables with probabilities of occurrence of .6 $\left(\mathrm{E}_{1}\right)$ and $.4\left(\mathrm{E}_{2}\right)$. On half the trials, $S$ was informed he would gain 10 cents for a correct event prediction, or lose 10 cents for an incorrect one. On the remaining trials, the level of risk was 1 cent. The sequence of risks was random with the restriction that half the $\mathrm{E}_{1}$ trials, and half the $\mathrm{E}_{2}$ trials were 10 cent risk and the remainder were 1 cent risk. The events were recorded on a 100-card deck which was shuffled before each trial block. Each $\mathrm{S}$ was given an initial stake of $\$ 1.00$ in chips. He was told there was no pattern in the event sequence, and that he would receive all money won during the experimental session. The $\mathrm{S}$ kept track of his wins and losses by taking or

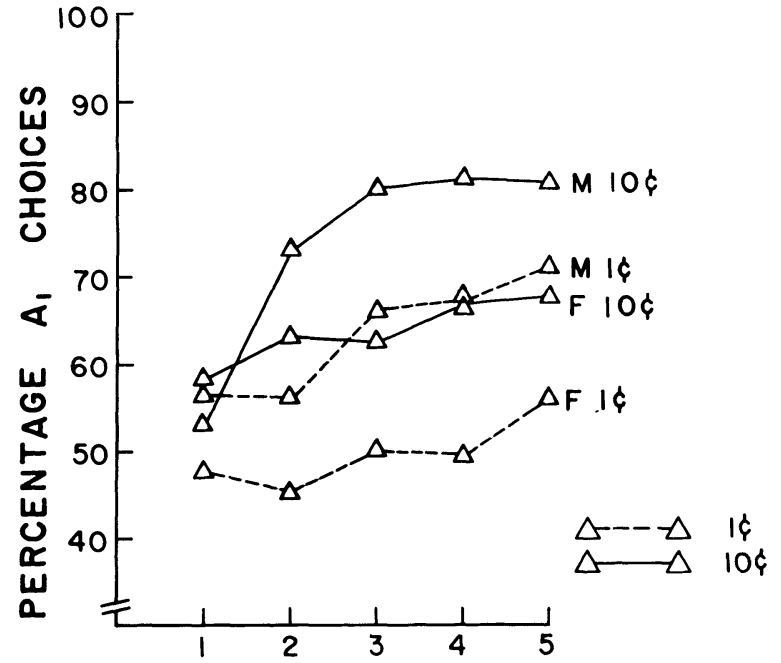

\section{BLOCKS OF 50 TRIALS}

Fig. 1. Percentage of $A_{1}$ choices for four combinations of risk and sex.

returning the appropriate amount from a "bank" of chips after each trial.

The second experiment was identical to the first except that a different $\mathrm{E}$ was used, and the events were geometric designs rather than nonsense syllables. An analysis of variance yielded low nonsignificant $F$ ratios for the $\mathrm{E}$ main effect and its interactions. The data from the two experiments were therefore combined, giving a total of 12 male and 12 female Ss.

\section{Results and Discussion}

Figure 1 shows the percentage of $\mathrm{A}_{1}$ choices, $\mathrm{P}\left(\mathrm{A}_{1}\right)$, for all four combinations of risk and sex over blocks of 50 trials. The data are reported in 50 trial blocks as each experimental block of 100 trials represented 501 cent-risk trials and 5010 cent-risk trials. The finding of major interest is that $P\left(A_{1}\right)$ is significantly greater for 10 cent than for 1 cent risk $(\mathrm{F}=5.89 ;$ df $1 / 22 ; \mathrm{p}<.025)$ contrary to human choice studies employing the absolute method of presenting risks (Myers et al, 1963; Edward \& Tannenbaum, 1961) but in agreement with Pubols' (1960) conclusion that differential incentive presentation does yield an incentive effect on animal behavior. The differences among the risk curves do not change significantly as a function of trials $(F=2.38$; df $4 / 88)$, although $P\left(A_{1}\right)$ does in- 
crease over trials $(F=15.58 ; \mathrm{df} 4 / 88 ; \mathrm{p}<.001)$. These results suggest that, while probability learning occurs slowly, risk level immediately initiates differential responding which is then stable over a large number of trials.

A second important, and somewhat puzzling, result is that male Ss not only made significantly nore $\mathrm{A}_{1}$ responses than female $\mathrm{Ss}$, but also showed a more rapid rate of learning throughout the first three trial blocks $(\mathrm{F}=4.16 ;$ df $4 / 88 ; \mathrm{p}<.01)$. Apparently, men were the more motivated Ss, but, contrary to all normal expectations in risk-taking behavior (Slovic, 1964), they were also the more conservative risk-takers. In two-choice experiments, the most risky approach is to attempt to be correct on every trial which results in probability matching, while the most conservative strategy is to choose the more frequent event on every trial. The male Ss in this experiment approached the latter strategy, while the female Ss were much closer to probability matching.

\section{References}

EDWARDS, W., \& TANNENBAUM, M. Probability learning with displays, instructions, and payoffs variant. Paper presented at Midwestern Psychological Association, 1961.

MYERS, J. L., FORT, J. G., KATZ, L., \& SUYDAM, M. M. Differential monetary gains and losses and event probability in a two-choice situation. J. exp. Psychol., 1963, 66, 521-522.

PUBOLS, P. Incentive magnitude, learning, and performance in animals. Psychol. Bull., 1960, 57, 89-155.

SLOVIC, P. Assessment of risk taking behavior. Psychol. Bull., 1964, $61,220-233$.

Note

1. This research was supported by funds from National Institutes of Health Grant MH-03803-04 and National Science Foundation Grant NSF GS-386. 